\title{
JM
}

Volume 7 No. 2 (Oktober 2019)

(C) The Author(s)

\section{FAKTOR PREDISPOSISING, PENDUKUNG DAN PENGUAT YANG MEMPENGARUHI PEMILIHAN ALAT KONTRASEPSI IUD CuT (COPPER T ) 380A PADA AKSEPTOR KB DI PUSKESMAS KOTA BENGKULU}

\author{
PREDISPOSISING, SUPPORTING AND STRENGTHENING FACTORS WHICH \\ INFLUENCES SELECTION OF 380A CUT (COPPER T) IUD CONTRACEPTION \\ IN KB ACCEPTORS IN PUSKESMAS, BENGKULU CITY
}

\author{
ASMARIYAH ${ }^{1}$, NOVIANTI ${ }^{2}$, LINDA YUSANTI $^{3}$ \\ DOSEN PRODI D3 KEBIDANAN FAKULTAS MIPA UNIVERSITAS BENGKULU \\ Email : asmarivah@unib.ac.id
}

\begin{abstract}
ABSTRAK
Penggunaan alat kontrasepsi IUD CuT 380 A mengalami penurunan setiap tahun, hasil SDKI 2012 penggunaan IUD masih rendah hanya 6\% dibandingkan dengan suntik Depo 32\%. Menurut data BKKBN kota Bengkulu penggunaan IUD oleh akseptor hanya 8,47\% dibandingkan dengan suntik KB 37,84\%. Banyak faktor yang memengaruhi pemilihan alat kontrasepsi diantaranya faktor predisposisi, pendukung dan penguat. Tujuan penelitian untuk mengetahui faktor predisposising, pendukung dan penguat yang memengaruhi pemilihan alat kotrasepsi IUD CuT 380A pada akseptor KB di kota Bengkulu.Metode Penelitian crossectional, pengambilan sampel secara sistematic random sampling. Penelitian dilakukan di 20 puskesmas kota Bengkulu. Sampel berjumlah 143 akseptor kontrasepsi. Data yang terkumpul melalui kuesioner dianalisis dengan chi square.Hasil penelitian faktor predisposisi yang terdiri dari usia, pekerjaan, jumlah anak yang diinginkan lagi, status ekonomi, pendapat yang salah tentang IUD, paritas dan pendidikan tidak memengaruhi dalam pemilihan alat kontrasepsi IUD CuT 380A. Faktor pendukung yang memengaruhi pemilihan alat kontrasepsi yaitu ketersediaan alat kontrasepsi, sedangkan tenaga pelayanan kesehatan tidak memengaruhi pemilihanan alat kontrasepsi IUD CUT 380A. Faktor pendorong yaitu dukungan suami, dukungan tenaga kesehatan, dukungan dari TOGA/TOMA dan efek samping alat kontrasepsi IUD tidak memengaruhi pemilihan alat kontrasepsi IUD pada akseptor KB di kota Bengkulu.Simpulan faktor yang memengaruhi pemilihan alat kontrasepsi adalah ketersediaan alat kontrasepsi. Perlu adanya pemberian informasi oleh tenaga kesehatan pada calon akseptor dengan melibatkan suami, pengadaan alat kontrasepsi hendaknya sesuai dengan sasaran KB.
\end{abstract}

Kata Kunci : IUD

\begin{abstract}
The using of IUD has decreased every year, the result of Indonesia SDKI 2012 showed that the using of IUD is still low, only $6 \%$ compared with the injection of Depo $32 \%$. According to data from BKKBN of Bengkulu city, the acceptor of IUD was only $8.47 \%$, compared to Injection of KB $37.84 \%$. Many factors affect contraceptive choice include predisposing factor, supporting
\end{abstract}


factors and driving factor. The aim of research to determine the factors which will affect the selection of the CuT 380A IUD contraceptive on family planning acceptors in Bengkulu city.This research method is cross sectional with systematic random sampling. Samples are 143 acceptors. Data were collected through questionnaires were analyzed with chi square.The results of the study of predisposing factors consisting of age, occupation, number of desirable children again, economic status, wrong opinions about IUDs, parity and education did not influence the choice of contraception. Supporting factors that influence the selection of contraceptives, while health care workers do not influence the choice of IUD CUT 380A contraceptives. The driving factor is husband's support, health personnel support, support from TOGA / TOMA and the side effects of IUD contraceptives did not affect the selection of IUD contraceptives in family planning acceptors in the city of Bengkulu. The conclusions of this study are factors affecting contraceptive choice; the availability of contraceptives, The health worker will need to provide information to potential acceptors by involving her husband, the procurement of contraceptives should be in accordance with the objectives

\section{Keywords: IUD}

\section{PEDAHULUAN}

Laju pertumbuhan penduduk di Indonesia semakin tahun semakin meningkat.. ${ }^{1}$ Peningkatan pertumbuhan penduduk di Indonesia bisa dikendalikan dengan program keluarga berencana, pemerintah memprioritaskan penggunaan metode kontrasepsi jangka panjang dalam hal ini IUD CuT 380A. ${ }^{2}$

Selain mengendalikan jumlah penduduk program KB juga bermanfaat untuk mewujudkan mutu kesehatan reproduksi yang baik bagi semua pada tahun 2015 seperti yang tercantum dalam Millenium Development Goals (MDGs) 2015 indikator 5b. ${ }^{2}$

Survei Demografi dan Kesehatan Indonesia (SDKI) selama periode $1991 \mathrm{~s} / \mathrm{d}$ 2007 menunjukkan pola penggunaan kontrasepsi MKJP khususnya IUD cenderung mengalami penurunan, yakni 13,3 persen (SDKI 1991), 10,3 persen (SDKI 1997) turun menjadi 6,2 persen (SDKI 2002-2003), dan turun lagi menjadi 4,9 persen (SDKI 2007), ${ }^{2}$ demikian juga dengan hasil SDKI 2012 penggunaan IUD masih rendah hanya $6 \%$ di bandingkan dengan suntik KB 32\% .

Alat kontrasepsi IUD saat ini diterima sebagai salah satu metode kontrasepsi terbaik yang tersedia dengan banyak kelebihan di bandingkan dengan kontrasepsi yag lain, pemerintah memprioritaskan penggunaan metode kontrasepsi jangka panjang dalam hal ini IUD CuT 380A karena IUD CuT 380A tidak megandung hormonal dan dapat melindungi terhadap kehamilan selama 8 tahun, tidak mempunyai efek samping yag berat dan sistemik.

Akseptor IUD berdasarkan hasil survey masih lebih rendah dibandingkan dengan akseptor suntik. Metode kontrasepsi suntik masih menjadi pilihan utama sebesar 27,8\%, dibandingkan dengan IUD yang masih cenderung menjadi bukan pilihan yang hanya $6,2 \%$ dari seluruh populasi pengguna kontrasepsi KB di Indonesia. Banyak faktor yang memengaruhi pemilihan alat kontrasepsi, penelitian terdahulu menemukan faktor sosiodemografi meliputi usia, paritas, pendidikan, status ekonomi, tempat tinggal, pendapatan keluarga bepengaruh terhadap pemilihan alat kontrasepsi. $3,4,5,6$

Pemilihan alat kontrasepsi IUD juga dipengaruhi oleh 1) rasa takut untuk menggunakan IUD dalam hal prosedur pemasangan terkait dengan rasa sakit saat pemasangan, bercak darah setelah pemasangan, IUD dapat keluar sendiri, darah haid lebih banyak, nyeri selama haid, 2) nilai negatif yang ada di masyarakat tentag IUD seperti : IUD dapat sebabkan kecacatan pada bayi, IUD dapat menembus rahim, 3) rasa malu untuk melakukan pemasangan alat kontrasepsi IUD karena harus menampakkan 
aurat. $^{7}$

\section{METODOLOGI PENELITIAN}

Rancangan penelitian yang digunakan adalah crossecsional dengan tujuan untuk menganalisis faktor karakteristik akseptor yang memengaruhi pemilihan alat kontrasepsi IUD Copper $T$ 380A dibandigkan dengan suntik KB Depo provera pada akseptror KB di puskesmas-puskesmmas kota Bengkulu.

Subjek penelitian adalah akseptor KB di kota Bengkulu yang memenuhi kriteria inklusi serta bersedia mengikuti penelitian. Pemilihan sampel menggunakan alokasi proporsional dengan menggunakan sistematic random sampling. Perhitungan besar sampel ditambahkan $10 \%$ sehingga di dapatkan sampel akhir sebesar 143 responden. Instrumen penelitian menggunakan kuesioner

\section{HASIL PENELITIAN}

Tabel 1. Distribusi Frekuensi faktor predisposisi, pendukung dan pendorong/penguat dalam pemilihan alat kontrasepsi IUD Copper $T$ 380A pada akseptor KB di puskesmas kota Bengkulu tahun 2018

\begin{tabular}{ccc}
\hline Variabel & N & Presentase (\%) \\
\hline $\begin{array}{c}\text { Faktor } \\
\text { Predisposisi/karakteristi } \\
\text { k akseptor }\end{array}$ & \\
\hline Usia & & \\
\hline$<20$ tahun & 63 & 44,1 \\
$20-34$ tahun & 79 & 52,2 \\
$\geq 35$ tahun & 1 & 0,7 \\
Pendidikan & & \\
\hline$<6$ tahun & 10 & 7 \\
\hline 6 tahun & 15 & 10,5 \\
\hline $7-9$ tahun & 27 & 18,9 \\
\hline $10-12$ tahun & 43 & 30,1 \\
\hline$>12$ tahun & 48 & 33,6 \\
\hline Paritas & & \\
\hline $1-2$ & 74 & 58,8 \\
\hline $3-4$ & 62 & 20,4 \\
\hline$\geq 5$ & 7 & 20,8 \\
\hline Pekerjaan & & \\
\hline IRT & 103 & 72 \\
\hline Buruh/petani & 7 & 4,9 \\
\hline
\end{tabular}

\begin{tabular}{|c|c|c|}
\hline Dagang/wiraswasta & 11 & 7,7 \\
\hline PNS & 19 & 13,3 \\
\hline Pegawai swasta & 3 & 2,1 \\
\hline \multicolumn{3}{|l|}{$\begin{array}{c}\text { Jumlah anak yang } \\
\text { diinginkan lagi }\end{array}$} \\
\hline 0 & 85 & 59,4 \\
\hline $1-2$ & 45 & 31,5 \\
\hline$\geq 3$ & 13 & 9,1 \\
\hline \multicolumn{3}{|l|}{ Status ekonomi } \\
\hline Tinggi & 54 & 37,8 \\
\hline Sedang & 19 & 13,3 \\
\hline Rendah & 70 & 49 \\
\hline \multicolumn{3}{|l|}{$\begin{array}{c}\text { Pendapat yang salah } \\
\text { tentang IUD }\end{array}$} \\
\hline Mendukung & 108 & 75,5 \\
\hline Tidak mendukung & 35 & 24,5 \\
\hline \multicolumn{3}{|l|}{$\begin{array}{c}\text { Faktor Pendukung } \\
\text { Ketersediaan alat } \\
\text { kontrasepsi }\end{array}$} \\
\hline Selalu tersedia & 135 & 94,4 \\
\hline Sering tidak tersedia & 8 & 5,6 \\
\hline \multicolumn{3}{|l|}{ Tenaga pelayaan } \\
\hline Dokter perempuan & 12 & 8,4 \\
\hline Dokter laki laki & 3 & 2,1 \\
\hline Bidan & 128 & 89,5 \\
\hline \multicolumn{3}{|l|}{$\begin{array}{c}\text { Faktor } \\
\text { Pendorong/penguat }\end{array}$} \\
\hline \multicolumn{3}{|l|}{ Dukungan suami } \\
\hline Mendukung & 17 & 11,9 \\
\hline Tidak mendukung & 126 & 88,1 \\
\hline \multicolumn{3}{|l|}{$\begin{array}{c}\text { Dukungan tenaga } \\
\text { kesehatan }\end{array}$} \\
\hline Mendukung & 124 & 88,7 \\
\hline Tidak mendukung & 19 & 13,3 \\
\hline \multicolumn{3}{|l|}{$\begin{array}{c}\text { Dukungan TOGA dan } \\
\text { TOMA }\end{array}$} \\
\hline Mendukung & 61 & 42,7 \\
\hline Tidak mendukung & 82 & 57,3 \\
\hline \multicolumn{3}{|l|}{ Efek samping } \\
\hline Tidak ada efek samping & 27 & 18,9 \\
\hline Gangguan haid & 101 & 70,6 \\
\hline Keputihan & 15 & 10,5 \\
\hline
\end{tabular}

Pada tabel 1 dapat dilihat bahwa faktor predisposisi pemilihan alat kontrasepsi IUD yaitu usia akseptor $\mathrm{KB}$ paling banyak usia 2034 tahun $(55,2 \%)$, pendidikan akseptor $\mathrm{KB}$ kebanyakan $>12$ tahun $(33,6 \%)$, paritas responden KB kebanyakan 1-2 orang (51\%), paling banyak pekerjaan Akseptor KB adalah IRT (Ibu Rumah Tangga), akseptor $K B$ banyak tidak menginginkan anak lagi (59,4\%), sebagian besar responden Akseptor 
KB mempunyai pendapat yang salah tentang $I U D$, responden akseptor $\mathrm{KB}$ dengan status ekonomi rendah.

Faktor pendukung didapatkan hasil bahwa sepengetahuan akseptor alat kontrasepsi IUD selalu tersedia dipuskesmas $(94,4 \%)$, Tenaga pelayanan yang memberikan pelayanan pada saat penggunaan alat kontrasepsi sebagian besar oleh bidan $(89,5 \%)$.

Faktor pendorong/penguat ; Responden akseptor KB mayoritas tidak mendapat dukungan suami untuk menggunkaan alat kontrasepsi IUD (88,1\%). sebagian besar mendapat dukungan dari tenaga kesehatan untuk menggunakan IUD, sebagian besar tidak mendapat dukungan dari tokoh agama dan tokoh masyarakat $(57,3)$, dan responden $K B$ mempunyai pengetahuan penggunaan IUD mempunyai efek samping.

Tabel 2. Distribusi frekuensi pendapat yang salah tentang IUD pada akseptor KB di puskesmas Kota Bengkulu

\begin{tabular}{ccc}
\hline Pendapat yang slah tentang IUD & $\mathrm{N}$ & Persentase \\
\hline $\begin{array}{c}\text { IUD dapat menyebabkan cacat } \\
\text { pada bayi }\end{array}$ & 51 & 35.7 \\
\hline $\begin{array}{c}\text { IUD dapat berpindah ketempat } \\
\text { lain dalam perut }\end{array}$ & 41 & 28.7 \\
\hline IUD dapat menembus rahim & 16 & 11.2 \\
\hline IUD dapat mencegah kehamilan & 35 & 24.5 \\
\hline Total & 143 & 100.0 \\
\hline
\end{tabular}

Pada tabel 2 dapat dilihat bahwa sebagian besar akseptor $\mathrm{KB}$ di puskesmas Kota Bengkulu mempunyai pendapat bahwa IUD dapat menyebabkan cacat pada bayi.

Tabel 3. Distribusi Frekuensi efek samping alat kontrasepsi IUD pada akseptor KB di puskesmas kota Bengkulu tahun 2018

\begin{tabular}{ccc}
\hline Efek Samping & $\mathrm{N}$ & Persentase \\
\hline Menstruasi tidak teratur & 42 & 29.4 \\
\hline Haid lebih lama dan banyak & 37 & 25.9 \\
\hline Pendarahan bercak & 8 & 5.6 \\
\hline Keputihan & 15 & 10.5 \\
\hline Nyeri haid & 14 & 9.8 \\
\hline Tidak ada & 27 & 18.9 \\
\hline Total & 143 & 100.0
\end{tabular}

Pada tabel 3 dapat dilihat bahwa sebagian besar efek samping dari alat kontrasepsi IUD CUT 380 A adalah Menstruasi tidak teratur 29,4\%

Tabel 4. Distribusi frekuensi penyebab takut untuk menggunakan IUD pada akseptor KB di puskesmas Kota Bengkulu yahun 2018

\begin{tabular}{ccc}
\hline $\begin{array}{c}\text { Penyebab Takut Menggunakan } \\
\text { IUD }\end{array}$ & $\mathrm{N}$ & Persentase \\
\hline Proses pemasangan & 102 & 71.3 \\
\hline IUD dapat keluar sendiri & 14 & 9.8 \\
\hline $\begin{array}{c}\text { IUD menyebabkan darah haid } \\
\text { banyak dan lama }\end{array}$ & 7 & 4.9 \\
\hline $\begin{array}{c}\text { IUD menyebabkan haid sangat } \\
\text { banyak }\end{array}$ & 8 & 5.6 \\
\hline $\begin{array}{c}\text { Cerita buruk tentang IUD } \\
\text { Total }\end{array}$ & 12 & 8.4 \\
\hline & 143 & 100.0 \\
\hline
\end{tabular}

Pada tabel 4 dapat dilihat bahwa akseptor KB di kota Bengkulu tidak menggunakan IUD CUT 380 A karena takut pada proses pemasangan

Tabel 5. Distribusi frekuensi malu untuk mengunakan IUD pada akseptor KB di kota Bengkulu tahun 2018

\begin{tabular}{ccc}
\hline $\begin{array}{c}\text { Malu menggunakan IUD } \\
\text { karena menampakkan aurat }\end{array}$ & $\mathrm{N}$ & Persentase \\
\hline Ya & 103 & 72.0 \\
\hline Tidak & 40 & 28.0 \\
\hline Total & 143 & 100.0 \\
\hline
\end{tabular}

Pada tabel 5 dapat dilihat bahwa sebagian besar akseptor KB di puskesmas kota Bengkulu tidak menggunakan IUD karena malu pada saat pemasangan menampakkan aurat. 
Tabel 6. Perbandingan faktor predisposisi yang memengaruhi pemilihan alat kontrasepsi IUD Copper $T$ 380A pada akseptor KB di puskesmas kota Bengkulu tahun 2018

\begin{tabular}{|c|c|c|c|c|c|c|}
\hline Variabel & IUD & & $\begin{array}{l}\text { Non } \\
\text { IUD }\end{array}$ & $\begin{array}{c}\text { Tot } \\
\text { al }\end{array}$ & $\%$ & $\begin{array}{l}\text { Nila } \\
\text { i p* }\end{array}$ \\
\hline & $\mathbf{N}$ & $\%$ & $\mathbf{N}$ & $\%$ & & \\
\hline \multicolumn{7}{|l|}{$\begin{array}{c}\text { Faktor } \\
\text { predisposisi }\end{array}$} \\
\hline Umur & & & & & & $\begin{array}{c}0,67 \\
2\end{array}$ \\
\hline$<20$ tahun & 12 & 38 & 51 & $4,3 \quad 63$ & 44,1 & \\
\hline 20-34 tahun & 19 & 61,3 & 60 & $\begin{array}{l}61,79 \\
9\end{array}$ & 55,2 & \\
\hline$\geq 35$ tahun & 0 & 0 & 1 & $0,8 \quad 1$ & 0,7 & \\
\hline Pendidikan & & & & & & $\begin{array}{c}0,36 \\
4\end{array}$ \\
\hline$<6$ tahun & 4 & 12,9 & 6 & $\begin{array}{ll}7,8 & 10 \\
\end{array}$ & 7 & \\
\hline 6 tahun & 2 & 6,5 & 13 & $11,7 \quad 15$ & 10,5 & \\
\hline 7-9 tahun & 8 & 25,8 & 19 & $17 \quad 27$ & 18,9 & \\
\hline 10-12 tahun & 9 & 29 & 34 & $\begin{array}{l}30,43 \\
4\end{array}$ & 30,1 & \\
\hline$>12$ tahun & 8 & 25,8 & 40 & $\begin{array}{c}35,48 \\
7\end{array}$ & 33,6 & \\
\hline Paritas & & & & 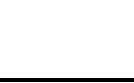 & & $\begin{array}{c}0,85 \\
8 \\
\end{array}$ \\
\hline 0 anak & 0 & 0 & 1 & $0,9 \quad 1$ & 0,7 & \\
\hline 1 anak & 14 & 3,2 & 59 & $\begin{array}{c}52,73 \\
7\end{array}$ & & \\
\hline 2 anak & 16 & 51,6 & 45 & $\begin{array}{cc}40, & 61 \\
2 & \end{array}$ & 42,7 & \\
\hline 3 anak & 1 & 3,2 & 5 & $4,5 \quad 6$ & 4,2 & \\
\hline 4 anak & 0 & 0 & 1 & $0,9 \quad 1$ & 0,7 & \\
\hline$>=5$ anak & 0 & 0 & 1 & $0,9 \quad 1$ & 0,7 & \\
\hline Pekerjaan & & & & & & $\begin{array}{c}0,93 \\
1 \\
\end{array}$ \\
\hline IRT & 21 & 67,7 & 82 & $\begin{array}{l}73,103 \\
2\end{array}$ & & \\
\hline Buruh/petani & 2 & 6,5 & 5 & $4,5 \quad 7$ & 14,9 & \\
\hline $\begin{array}{l}\text { Pedagang/wiras } \\
\text { wasta }\end{array}$ & 2 & 6,5 & 9 & $\begin{array}{ll}8 & 11\end{array}$ & 7,7 & \\
\hline PNS & 5 & 16,1 & 14 & $\begin{array}{c}12,19 \\
5\end{array}$ & 13,3 & \\
\hline Pegawai swasta & 1 & 3,2 & 2 & $1,8 \quad 3$ & 2,1 & \\
\hline $\begin{array}{c}\text { Jumlah anak } \\
\text { yang diinginkan } \\
\text { lagi } \\
\end{array}$ & & & & & & $\begin{array}{c}0,57 \\
6\end{array}$ \\
\hline $\begin{array}{l}\text { Tidak ingin anak } \\
\text { lagi }\end{array}$ & 17 & 54,8 & 68 & $\begin{array}{c}60,85 \\
7\end{array}$ & 59,4 & \\
\hline $1-2$ & 12 & 38,7 & 33 & $\begin{array}{c}25,45 \\
5\end{array}$ & 31,5 & \\
\hline$\geq 3$ & 2 & 6,5 & 11 & $9,8 \quad 13$ & 9,1 & \\
\hline Pendapat yang & & & & & & 0,12 \\
\hline
\end{tabular}

\begin{tabular}{|c|c|c|c|c|c|}
\hline $\begin{array}{l}\text { salah tentang } \\
\text { IUD }\end{array}$ & & & & & 4 \\
\hline Mendukung & 19 & 61,3 & 89 & $\begin{array}{l}70,10875,5 \\
5\end{array}$ & \\
\hline $\begin{array}{c}\text { Tidak } \\
\text { mendukung }\end{array}$ & 12 & 38,7 & 23 & $\begin{array}{ccc}20, & 35 & 24,5 \\
5 & & \\
\end{array}$ & \\
\hline Status ekonomi & & & & & $\begin{array}{l}, 30 \\
0\end{array}$ \\
\hline Tinggi & 8 & 25,8 & 54 & $\begin{array}{lll}41 & 54 & 37,8 \\
\end{array}$ & \\
\hline Sedang & 5 & 16,1 & 14 & $\begin{array}{ccc}12, & 19 & 13,3 \\
5 & & \\
\end{array}$ & \\
\hline Rendah & 18 & 58,1 & 52 & $\begin{array}{ccc}46, & 70 & 49 \\
4 & & \end{array}$ & \\
\hline
\end{tabular}

Berdasarkan tabel 6 dapat dilihat bahwa faktor predisposisi tidak memengaruhi pemilihan alat kontrasepsi IUD Cooper $T$ 380A pada akseptor KB di puskesmas kota Bengkulu.

Tabel 7. Perbandingan faktor pendukung dan penguat yang memengaruhi pemilihan alat kontrasepsi IUD CUT 380 A pada akseptor KB di puskesmas kota Bengkulu tahun 2018

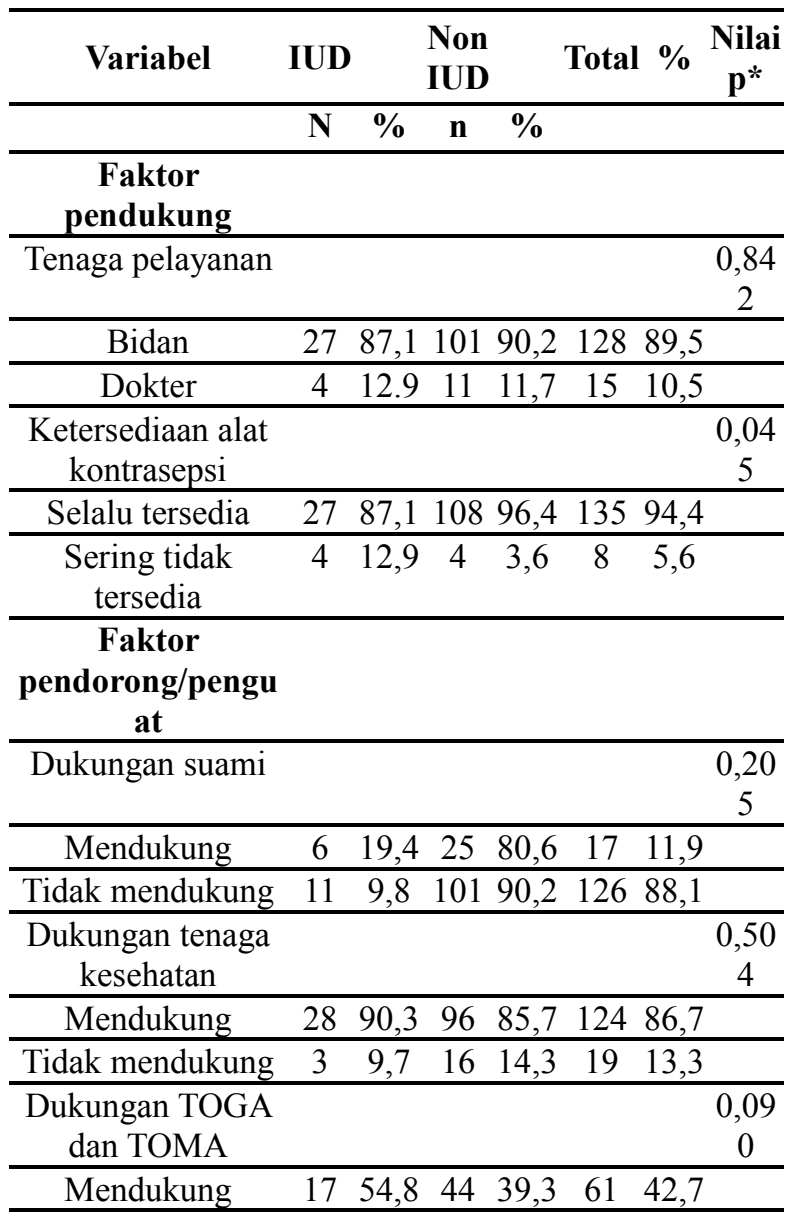




\begin{tabular}{ccccccccc}
\hline Tidak mendukung & 14 & 45,2 & 68 & 60,7 & 82 & 57,3 \\
\hline Efek samping & & & & & & & 0,43 \\
& & & & & & 4 \\
\hline $\begin{array}{c}\text { Tidak ada efek } \\
\text { samping }\end{array}$ & 8 & 25,8 & 19 & 17 & 27 & 18,9 & \\
\hline Gangguan haid & 21 & 67,7 & 80 & 71,4 & 101 & 70,6 \\
\hline Keputihan & 2 & 6,5 & 13 & 11,6 & 15 & 10,5 \\
\hline
\end{tabular}

Tabel 7 dapat dilihat bahwa faktor pendukung yang memengaruhi pemilihan alat kontrasepsi IUD Copper T 380A pada akseptor KB di puskesmas kota Bengkulu tahun 2018 adalah ketersediaan alat kontrasepsi nilai $\mathrm{p}=0,045$.

\section{PEMBAHASAN}

Faktor pendidikan berdasarkan uji statistik di dapatkan nilai $\mathrm{p}=0,368$ yang berarti tidak ada pengaruh pendidikan terhadap pemilihan kontrasepsi IUD copper $T$ $380 \mathrm{~A}$ pada akseptor KB di kota Bengkulu. Mengacu pada fakta-fakta bahwa permasalahannya lebih terletak pada tingkat kesadaran masyarakat terhadap norma keluarga kecil, tingkat kesadaran terhadap norma keluarga kecil relatif tidak berbeda, bahkan fakta empiriknya cukup kontroversial dimana mereka yang berpendidikan tinggi memiliki tingkat fertilitas lebih tinggi dibandingkan yang berpendidikan rendah. Kondisi yang demikianlah barangkali yang menyebabkan partisipasi terhadap penggunaan kontrasepsi relatif tidak berbeda.

Hasil penelitian pada usia 20-34 tahun lebih banyak responden menggunakan non $I U D$ dibanding dengan $I U D$, Penelitian lain menyebutkan usia pada pengguna IUD 21,9\% lebih dari 40 tahun, rata-rata usia 32 tahun. Usia dikaitkan dengan risiko kegagalan secara signifikan lebih rendah pada usia 35 tahun. Wanita yang berusia lebih muda lebih besar mengalami kegagalan dibandingkan dengan wanita usia lebih dari 35 tahun. Berdasarkan analisis uji statistik chi kuadrat didapatkan bahwa usia tidak memengaruhi penggunaan alat kontrasepsi IUD copper $T$.

Paritas dalam penelitian ini di dapatkan hasil bahwa pengguna IUD copper $T$ banyak digunakan pada paritas 2 sedangkan pengguna non IUD paling banyak pada akseptor yang mempunyai paritas 1 . Penelitian ini juga serupa dengan hasil penelitian lain yang menyatakan paritas pada pengguna IUD paritas 2 dan 3 serta 2,3\% memiliki paritas 5 atau lebih.

Berdasarkan uji statistik chi kuadrat didapatkan hasil $\mathrm{p}=0,931$ yang menunjukkan bahwa ttidak terdapat pengaruh antara pekerjaan dengan pemilihan alat kontrasepsi IUD dibandingkan dengan non IUD.

Hasil penelitian pada variabel jumlah anak yang diinginkan lagi pada pengguna $I U D$ dan non IUD adalah terbanyak pada responden tidak ingin punya anak lagi 85 responden dari 85 responden 17 (20\%) menggunakan IUD dan 68 (80\%) menggunakan no IUD. Hasil ini dapat dilihat bahwa untuk responden yang tidak ingin punya anak lagi lebih banyak menggunakan alat kontrasepsi non IUD dibandingkan dengan menggunakan IUD di mana alat kontrasepsi $I U D$ merupakan alat kotrasepsi jangka panjang dapat melindungi terhadap kehamilan selama 8 tahun.

Berdasrkan uji analisis statistik chi kuadarat didapatkan hasil $\mathrm{p}=0,124$, hasil statistik ini menunjukkan bahwa tidak terdapat pengaruh yang signifikan antara pendapat yang salah tentang IUD terhadap pemilihan alat kontrasepsi IUD. Hasil penelitian ini adanya pendapat yang salah di masyarakat tentang IUD yaitu IUD bisa berjalan jalan di dalam perut, menembus rahim dan menyebabkan cacat pada bayi sehingga responden tidak mau menggunakan IUD karena pendapat yanng salah ini menimbulkan rasa takut pada akseptor dan menyebabkan IUD tidak aman untuk digunakan.

Penelitian ini hampir semua responden baik yang memilih alat kontrasepsi IUD maupun Depo mendapatkan pelayanan penggunaan alat kontrasepsi dengan bidan, sehingga bidan harus selalu meningkatkan pengetahuan.

Ketersediaan alat kontrasepsi IUD sangat mendukung dalam penggunaan IUD, untuk itu hendaknya puskesmas dalam 
membuat permintaan alat kontrasepsi untuk puskesmas sebaiknya berdasarkan sasaran KB sehingga alat kontrasepsi selalu ada pada saat akseptor ingin menggunakan.

Berdasarkan hasil analisis fertilitas provinsi bengkulu yang menyatakan bahwa dukungan suami dalam penggunaan alat kontrasepsi kurang karena para suami atau laki laki menganggap $\mathrm{KB}$ itu adalah urusan istri atau wanita, hal ini sesuai dengan jawaban dari responden bahwa penggunaan alat kontrasepsi terserah akseptor saja.

Dari hasil penelitian ini dapat disimpulkan bahwa akseptor yang mendapat dukungan dari tenaga kesehatan maka akseptor lebih memilih menggunakan alat kontrasepsi IUD dan sebaliknya akseptor yang tidak mendapatkan dukungan dari tenaga kesehatan lebih memilih tidak menggunakan alat kotrasepsi IUD.

Dukungan TOGA/TOMA cukup berpengaruh dalam memberikan peyuluhan atau informasi untuk ber-KB, wanita yang mendapatkan inforasi $\mathrm{KB}$ dari tokoh agama dan tokoh masyarakat mempunyai peluang untuk memakai MKJP lebih tinggi 1,7 kali dari pada yang tidak mendapatkan informasi.

Pertimbangan keuntungan dan kerugian setiap jenis kontrasepsi juga merupakan alasan pemilihan alat kontrasepsi. ${ }^{8}$ selain faktor keuntungan dan kerugian, beberapa efek samping penggunaan metode kontrasepsi juga memengaruhi kelangsungan pemakaian alat kontrasepsi. Faktor efek samping dari CuT 380A yang paling sering untuk berhenti menggunakan IUD $\mathrm{CuT}$ adalah perdarahan dan dismenorrhoe

\section{KESIMPULAN}

Faktor yang memengaruhi pemilihan alat kontrasepsi IUD CuT 380A pada akseptor KB di Kota Bengkulu adalah faktor pendukung yaitu ketersediaan alat kontrasepsi.

\section{SARAN}

Diharapkan kepada Peneliti selanjutnya untuk lebih mengembangkan penelitian mengenai Kontrasepsi IUD CuT dengan menggunakan desain penelitian yang lebih baik lagi.

\section{DAFTAR PUSTAKA}

Adolescent Women Using the IUD. J Pediatr Adolesc Gynecol 28 (2015) 38e42 http://dx.doi.org/10.1016/j.jpag.2014.02 .015

BADAN PUSAT STATISTIK (BPS). Jumlah Penduduk Indonesia Tahun 2010. Retrieved from http://www.bps.go.id/menutab.php? tabel $=1 \& \mathrm{~kat}=1 \& \mathrm{id}$ subyek $=12: 2010$

de Araujo, F. F., Barbieri, M., Guazzelli, C. A. F., \& Lindsey, P. C. (2008). The T 380A intrauterine device: a retrospective 5year evaluation. Contraception, 78 (2008),

474-8. doi:10.1016/j.contraception.2008.07.00 6

Friedman Joy O, MD. Factors Associated with Contraceptive Satisfaction in

Glanz Karen, Barbara K. Rimer, K. Viswanath. Health Behavior and Health Education Theory, Research and Practice. 4th ed. Jossey Bass A Wiley Imprint 989 Market Street, San Francisco, CA 94103-1741www.josseybass.com

Imbarwati. Beberapa faktor yang berkaitan dengan penggunaan KB IUD pada peserta KB non IUD di kecamatan Pendurungan kota Semarang. Universitas diponegoro 2009 (tesis)

Johana D, Agnes M, Gresty M. Faktor-faktor yang Berhubungan dengan Pemilihan Alat Kontrasepsi Dalam Rahim (AKDR) bagi Akseptor KB di Puskesmas Jailolo. Jurnal e.Ners Maret 2013 (eNS) Vol 1 No 1

Kaneshiro, Aeby Tod. Long-term safety, efficacy, and patient acceptability of the intrauterine Copper T-380A contraceptive device. International Journal of Women's Health 2010:2 211220.

Khan Shazia A, Amin Zain UI, Fouzia, 
Jadoon S. A Comparative Trial OF Cooper $\mathrm{T}$ 380A ang $\mathrm{Cu}$ 375IUCD. J Ayub Med Coll Abbottabad 2010;22(3) http://www.ayubmed.edu.pk/JAMC/PA ST/22-3/ShaziaKhan.pdf

Nisa Khairun Neneng, Susilani Tri Amalia, Hadnisari Nina. Persepsi tentang IUD pada wanita usia subur di BPS Widya dusun Juwangen kelurahan Purwomartani kecamatan Kalasan Kabupaten Sleman. Jurnal Permata Indonesia Volume 6 Nomor 2, November 2015, halaman 46-56. ISSN 2086-9185.

Pastuti, R., \& Wilopo, S. A. DETERMINAN PENGGUNAAN METODE KONTRASEPSI IUD DI INDONESIA ANALISIS DATA SDKI 2002-2003. Berita Kedokteran Masyarakat, 23(2), 71-80:2007

Puspitasari D, Winarni E, Kajian implementasi Kebijakan penggunaan Kontrasesapsi IUD. Pusat Penelitian dan Pengembangan KB KS-Badan Kependudukan dan keluarga Berencana Nasional; 2011

Salem RM, Setty V, Williamson RT, Schwandt H. When contraceptives change monthly bleeding. Popul Rep J 2006:1, 3-1,19. 